\title{
Engineered 2D polymers: current status and future trend
}

\begin{abstract}
Extending the concept of synthesizing $2 \mathrm{~d}$ polymer sheets has been explored in this mini review to highlight about the future potentials inherent with this important class of engineered materials. The discovery of graphene (i.e. mechanically and chemically robust highly crystalline nano sheets with extremely high charge carrier mobility) not only dispelled the thermodynamic instability of $2 \mathrm{D}$ materials but also established it as a material for ultrafast, and low power nanoelectronic devices besides motivating to look for other 2D materials to get rid of the zero band gap limitation of graphene causing poor 'on/off' ratio for switching applications.
\end{abstract}

Volume I Issue I - 2017

\author{
S Ahmad, GK Moinudeen \\ Confederation of Indian Industry, India
}

Correspondence: S Ahmad, Confederation of Indian Industry, 508 Brentwood Tower, Eros Garden, Charmwood Village, Faridabad, Haryana, India, Tel 0091-98/8137484,

Email drsahmad@email.com

Received: February 06, 2017| Published: February 20, 2017

\section{Introduction}

In this search for the alternatives, surface-mediated growth of molecular assemblies on metal substrates using planar aromatic molecular building blocks was considered with conjugated backbones that were suitable for directional inter-molecular coupling leading to 1/2-D covalent and no covalent assemblies with precursor dependent forms and functions where relative strength and directionality of the intermolecular interactions were found to control the resultant molecular architectures facilitated by host-guest-networks, or growth templates.

These nanostructures could be made to possess high charge carrier mobilities due to strong intermolecular coupling during their onsurface polymerization resulting in surface-confined 2D nanosheets. In this context, the organic macromolecules with programmable structure, composition, and functionalities became handy for their uses in (opto) electronic devices. Additionally, designing atomically precise pores would make them useful in membranes or sensors as shown in poly (para-phenylene) or graphene ${ }^{1}$ nano ribbons. However, it would be essential to improve the quality of highly defective 2DPs that were synthesized initially lacking long-range orders by initiating polymerization on metal surfaces as template, wherefore different substrate materials, coupling reactions, and reaction parameters are possible to control the quality covalent networks better. ${ }^{2}$

Compared to a linear chain of polymer with each monomer linked to two neighbors in 1D-architecture, a two-dimensional polymer sheet (2DPS) contains covalently bonded molecular building blocks extending in 2D.,3 Preparation of mono/few-layer of materials from natural and synthetic lamellar crystals exfoliated into nanosheets (as in case of graphene) is known to face problems in their synthesis, and production although characteristic (opto) electronic properties of their mono/few layered structures have been found possessing novel applications. Given the progress made in synthesizing these engineered 2DP sheets from available starting materials, the future prospects appear bright once larger sheets are produced with added functionalities incorporated on one/both sides. Enlarging the types of monomers involved in preparing 2DP sheets through different polymerization routes would certainly broaden the range of resultant engineered materials. Having overcome the current problems of design and synthesis of these monomers, the production of 2DP in quantity is expected soon in due course of time. ${ }^{5}$
Structurally engineered 2D Ps are the marvels of current synthetic chemistry creating mono/few-layer sheets with periodic internal structures and functional groups placed at predetermined sites. Various aspects of these unique materials were discussed recently including their structural architectures, elastic strength, percolation, persistence, and co-polymeric growth kinetics along with their potentials of applications. ${ }^{6}$

Covalent organic frameworks $\left(\mathrm{COF}_{\mathrm{s}}\right)$ are crystalline polymers ${ }^{7}$ in which organic building blocks are topologically linked into extended lattice structures with periodic skeletons and ordered pores compared to other crystalline porous materials allowing for precise design and control over both skeletons and pores. The 2D COF form 2DP sheets comprising of periodic columnar $\pi$-arrays and orientated onedimensional (1D) channels. By virtue of their ordered $\pi$-structure and high porosity, $\mathrm{COF}_{\mathrm{s}}$ have emerged as a powerful platform for designing functional materials and have shown outstanding performance in various fields, including gas adsorption, light emitters, catalysis, semiconductors, proton conductions and energy conversion and storage..$^{8-9}$

$\mathrm{COF}_{\mathrm{s}}$ are typically synthesized via topologically directed $[1+1]$ condensation reactions between a knot and a linker unit together. For example, a maximum of 10 different $\mathrm{COF}_{\mathrm{s}}$ are possible to synthesize from a library of one knot and 10 linkers. A general multiplecomponent (MC) strategy was reported allowing for more than two components for the topological design and practical synthesis of $\mathrm{MC}-\mathrm{COF}_{\mathrm{s}}$, which are formed in a single phase with permanent porosity and high crystallinity, irrespective of their components and topologies. This strategy has been found effective in enhancing the structural diversity of $\mathrm{COF}_{\mathrm{s}}$, and a collection of one $\mathrm{C}_{3}$-symmetric vertex and $10 \mathrm{C}_{2}$-symmetric linkers can generate 210 new hexagonal $\mathrm{MC}-\mathrm{COF}_{\mathrm{s}}$ accordingly. The capability of the proposed scheme was demonstrated by synthesis of $53 \mathrm{COF}_{\mathrm{s}}$ by condensing one knot with two or three linkers to produce hexagonal $\mathrm{MC}-\mathrm{COF}_{\mathrm{s}}$ and two linkers to prepare tetragonal $\mathrm{MC}-\mathrm{COF}_{\mathrm{s}}$. Unlike conventional $[1+1] \mathrm{COF}_{\mathrm{s}}$, $\mathrm{MC}-\mathrm{COF}_{\mathrm{s}}$ demonstrated enhanced complexity in both skeletons and pores by creating sequenced anisotropic tiling and unusually shaped ordered pores. Further, it was shown possible to employ multiplecomponent electron donor-acceptor COFs triggering strong electronic correlations among the latticed $\pi$-components exhibiting enhanced electronic properties. ${ }^{8-9}$ 
Alternately, it is also possible to consider 2DPs as a lamellar form of covalent organic frameworks $\left(\mathrm{COF}_{\mathrm{s}}\right)$ designed and synthesized from extended crystalline organic porous structures made from light elements $(\mathrm{H}, \mathrm{B}, \mathrm{C}, \mathrm{N}$, and $\mathrm{O})$ known to form strong covalent bonds in materials like diamond, graphite, and boron nitride. These $\mathrm{COF}_{\mathrm{s}}$ prepared using molecular building blocks would provide covalent frameworks that would be possible to functionalize forming lightweight materials for diverse applications. These crystalline porous polymeric materials are emerging as atomically precise integration of organic units extended into 2D structures with periodic skeletons and ordered programmable nanopores decided by the geometry and dimensions of the building blocks involved in the topological evolution of structural periodicity. The diversity possible in the building blocks and covalent linkage topology schemes make these $\mathrm{COF}_{\mathrm{s}}$ as unique platforms having structurally controlled functional designs offering confined molecular spaces for the interplay of photons, excitons, electrons, holes, ions and guest molecules, and thereby exhibiting unique physico-chemical properties as discussed in a recent review. ${ }^{8-9}$

For example, frequent observations of lower crystallinity in $\mathrm{COF}_{\mathrm{s}}$ with different linkages and building blocks involving topdown exfoliation and bottom-up surface synthesis were taken care of recently by a self-limiting solid-vapor interface reaction to produce ordered structures by modifying the coupling reactions at the solidvapor interface by introducing one precursor via vaporization to the surface preloaded with the other resulting in honeycomb $\mathrm{COF}_{\mathrm{s}}$ with imine linkage as demonstrated. ${ }^{5}$

Fluorinated 2DP thin sheets $(\sim 1 \mathrm{~nm}$ thick with $\sim 0.9 \mathrm{~nm}$ diameter pores of $3.3 \times 10^{13}$ pores $/ \mathrm{cm}^{2}$ density) were exfoliated from preorganized lamellar crystal comprising of three photo-reactive arms, photo-polymerization of crystalline monomers by [4+4] cyclo addition, and isolation of individual $2 \mathrm{DP}$ polymer. ${ }^{10} \mathrm{~A}$ non-centrosymmetric, and enantio-morphic mono crystalline monomer was photo-chemically converted into chiral 2D polymeric crystals and reversed back to the monomer with an all-carbon scaffold and synthesized (i.e. on gram scale) where the monomer was highly robust, grown to sizes greater than $1 \mathrm{~mm}$ and the resulting 2DP crystals were exfoliated into nano sheets useful in membranes and nonlinear optics. ${ }^{11}$

One-step preparation of $\mathrm{COF}_{5}$ combining $\mathrm{C}_{3}$ and $\mathrm{C}_{2}$-symmetric building blocks forming triangular micropores ${ }^{12}$ of different sizes and chemical environments: $1.13 \mathrm{~nm}$ and $1.52 \mathrm{~nm}$, as confirmed by $\mathrm{XRD}$, and nitrogen adsorption/desorption measurements. ${ }^{13}$ In another study, three versions of $\mathrm{COF}_{\mathrm{s}}$ containing distribution of $\pi$-conjugated dehydrobenzoannulene (DBA) on vertices were reported involving different ratios of $\mathrm{C}_{3} / \mathrm{C}_{2}$-symmetric DBA catechol and pyrene-2,7diboronic acid (PDBA) to produce three samples namely - Py-DBA$\mathrm{COF}_{1}$, Py-DBA-COF , and Py-MV-DBA-COF with luminescent properties. ${ }^{14}$ Even two different pores bearing $\mathrm{CFO}_{\mathrm{s}}$ were reported through condensation reactions of two $\mathrm{D}_{2 \mathrm{~h}}$ symmetrical building blocks exhibiting good adsorption capacities for $\mathrm{CO}_{2}$ and $\mathrm{H}_{2} \cdot{ }^{13}$

In continuation, a porous $\left(\mathrm{SA}_{\mathrm{BET}}=5083 \mathrm{~m}^{2} / \mathrm{g}\right) 3 \mathrm{D} \mathrm{COF}$ was synthesized with a record low density $\left(0.13 \mathrm{~g} / \mathrm{cm}^{3}\right)$ containing $\pi$-electron conjugated dehydrobenzoannulene ${ }^{14}$ (DBA) units in which metalation of DBA-3D-COF 1 with Ni to produce Ni-DBA-3D-COF resulting in a minimal reduction in surface area $\left(\mathrm{SA}_{\mathrm{BET}}=4763 \mathrm{~m}^{2} / \mathrm{g}\right)$ due to metal incorporation within DBA cavity, and retention of crystallinity besides displaying higher uptake capacities for ethane and ethylene gas. ${ }^{15}$
A highly emissive COF design was presented by introducing an aggregation-induced emission (AIE) mechanism into the polygon vertices giving crystalline porous $\mathrm{COF}_{\mathrm{s}}$ with periodic $\pi$-stacked columnar arrays that enhanced the luminescence of the $\mathrm{COF}_{\mathrm{s}}$, via a synergistic structural locking effect of intra-layer covalent bonding and interlayer non covalent $\pi$ - $\pi$ interactions while working as a sensor for ammonia down to sub ppm level. ${ }^{16}$

The special advantages associated with these engineered 2DP sheet materials are foreseen by affecting simultaneous control of porosity, strength, and flexibility combined with realization of programmable charge carrier transport and optoelectronic properties for a number of novel applications. Selecting appropriate functional building blocks would not only offer solutions to a number of structural issues related problems affecting stability of the functional components and devices fabricated but also enable fabrication of newer devices not yet known.

A large-area thin film of a conjugated, imine-based, twodimensional COF was synthesized at the solution/air interface having 2-200nm thickness. Films were transferred to another substrate by lifting from underneath, enabling their use as the semiconducting active layer in field-effect transistors. ${ }^{17}$

\section{Acknowledgements}

None.

\section{Conflict of interest}

The author declares no conflict of interest.

\section{References}

1. Chen L, Hernandez Y, Feng X, et al. From nano graphene and graphene nanoribbons to graphene sheets: chemical synthesis. Angew Chem Int Ed Engl. 2012;51(31):7640-7654.

2. Eichhorn JE. On-Surface Synthesis of Two-Dimensional Organic Nanostructures. $\mathrm{PhD}$ thesis submitted to Fakultat fur Physik der. Germany: Technischen Universitat Munchen; 2014. p. 1-118.

3. Colson JW, Dichtel WR. Rationally synthesized two-dimensional polymers. Nature Chemistry. 2003;5:453-465.

4. Payamyar P, King BT, Öttinger HC, et al. Two-dimensional polymers: concepts and perspectives. Chem Commun (Camb). 2016;52(1):18-34.

5. Liu XH, Guan CZ, Ding SY, et al. On-surface synthesis of single-layered two-dimensional covalent organic frameworks via solid-vapor interface reactions. J Am Chem Soc. 2013;135(28):10470-10474.

6. Paton KR, Varrla E, Backes C, et al. Scalable production of large quantities of defect-free few-layer graphene by shear exfoliation in liquids. Nat Mater. 2014;13(6):624-630.

7. Sakamoto J, van Heijst J, Lukin O, et al. Two-dimensional polymers: Just a dream of synthetic chemists? Angew Chem Int Ed Engl. 2009;48(6):1030-1069.

8. Huang N, Zhai L, CoupryD E, et al. Multiple-component covalent organic frameworks. Nat Commun. 2016;7:12325.

9. Huang N, Wang P, Donglin Jiang D. Covalent organic frameworks: a materials platform for structural and functional designs. Nature Reviews Materials. 2016;1:16068.

10. Kissel P, Murray DJ, Wulftange WJ, et al. A nanoporous two-dimensional polymer by single-crystal-to-single-crystal photo polymerization. Nat Chem. 2014;6(9):774-778.

11. Kory MJ, Wörle M, Weber T, et al. Gram-scale synthesis of twodimensional polymer crystals and their structure analysis by X-ray diffraction. Nat Chem. 2014;6(9):779-784. 
12. Xu SQ, Zhan TG, Wen Q, et al. Diversity of covalent organic frameworks (COFs): A 2D COF containing two kinds of triangular micropores of different sizes. ACS Macro Lett. 2016;5(1):99-102.

13. Tian Y, Xu SQ, Qian C, et al. Two-dimensional dual-pore covalent organic frameworks obtained from the combination of two $D_{2 b}$ symmetrical building blocks. Chem Commun (Camb). 2016;52(78):11704-11707.

14. Crowe JW, Baldwin LA, McGrier PL. Luminescent covalent organic frameworks containing a homogeneous and heterogeneous distribution of dehydrobenzoannulene vertex units. J Am Chem Soc. 2016;138(32):10120-10123.
15. Baldwin LA, Crowe JW, Pyles DA, et al. Metalation of a mesoporous three-dimensional covalent organic framework. J Am Chem Soc. 2016;138(46):15134-15137.

16. Dalapati S, Jin E, Addicoat M, et al. Highly emissive covalent organic frameworks. J Am Chem Soc. 2016;138(18):5797-5800.

17. Feldblyum JI, McCreery CH, Andrews SC, et al. Few-layer, largearea, 2D covalent organic framework semiconductor thin films. Chem Commun. 2015;51:13894-13897. 